\title{
LA-UR-15-22549
}

Approved for public release; distribution is unlimited.

Title: $\quad$ Enhancing Situational Awareness for Infectious Disease Surveillance

Author(s): $\quad$ Daughton, Ashlynn Rae

Deshpande, Alina

Generous, Eric Nicholas Alexandre

Intended for: Handout describing tools

Issued:

2015-04-09 
Disclaimer:

Los Alamos National Laboratory, an affirmative action/equal opportunity employer,is operated by the Los Alamos National Security, LLC for the National NuclearSecurity Administration of the U.S. Department of Energy under contract DE-AC52-06NA25396. By approving this article, the publisher recognizes that the U.S. Government retains nonexclusive, royalty-free license to publish or reproduce the published form of this contribution, or to allow others to do so, for U.S. Government purposes. Los Alamos National Laboratory requests that the publisher identify this article as work performed under the auspices of the U.S. Departmentof Energy. Los Alamos National Laboratory strongly supports academic freedom and a researcher's right to publish; as an institution, however, the Laboratory does not endorse the viewpoint of a publication or guarantee its technical correctness. 
Tools validated with users through demos and webinars at international conferences, agency workshops, technology showcases, and biosurveillance working groups

\section{Development of LANL} Biosurveillance Gateway, available at: bsv.lanl.gov

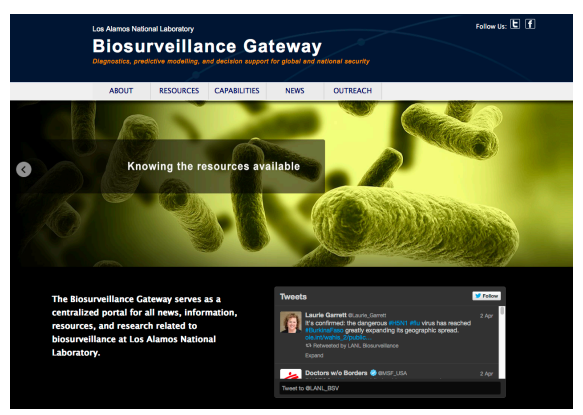

- Curated relational database of biosurveillance products and tools available worldwide

- Systematic and structured categorization based on biosurveillance system and data stream framework developed at LANL

- Searchable by multiple keywords geographic location, disease, sponsoring agency, contacts, data streams, etc.

- Linked to resource websites, contact information and associated documents Available at: brd.lanl.gov

\section{Biosurveillance Resource Database}

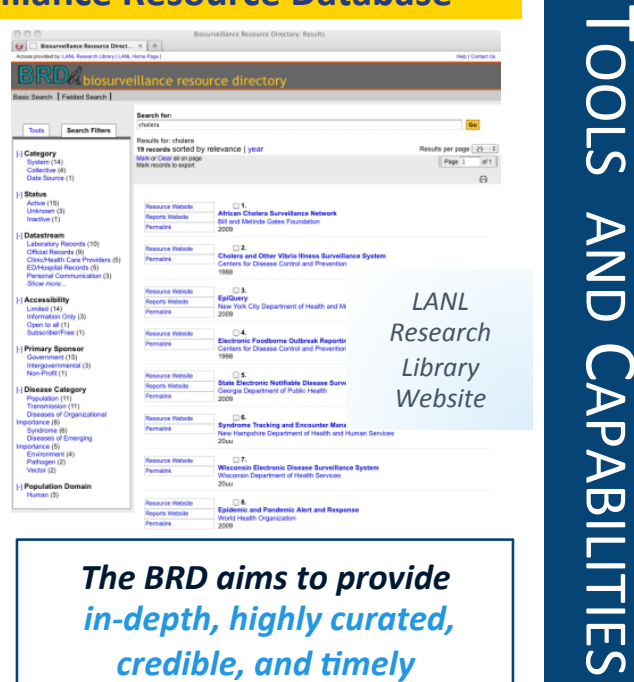

information relating to all aspects of biosurveillance

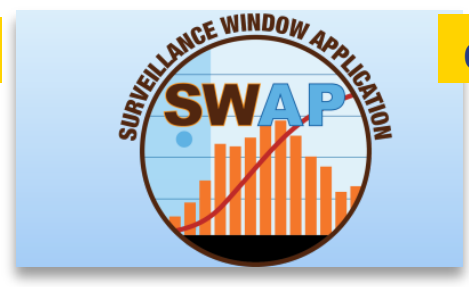

- Contextualizes information during an infectious disease outbreak

- Places a frame of reference for where a case count maybe during an outbreak

Outbreak Situational Awareness App

- Provides specific information about an operational model that has been comprehensively categorized

- Provides links to specific models with updated and accurate contact information for a model facilitating its immediate use

- Is a model characterization tool -Framework applicable to new models that may be included in the future

Results \begin{tabular}{l} 
Found 8 dises \\
ID Name \\
\hline $12 \quad$ Malar
\end{tabular}

- Will offer precision through its 12 Malaria Alas Project MAAP) search and find function

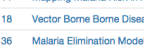

- Coming Spring 2015!

$\begin{array}{ll}13 & \text { Chaterese, } M \\ 23 & \text { Openmalara }\end{array}$

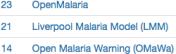

Determines whether the unfolding events are still within a surveillance window

- Suggests additional information sources to support decision making

Available at: swap.lanl.gov

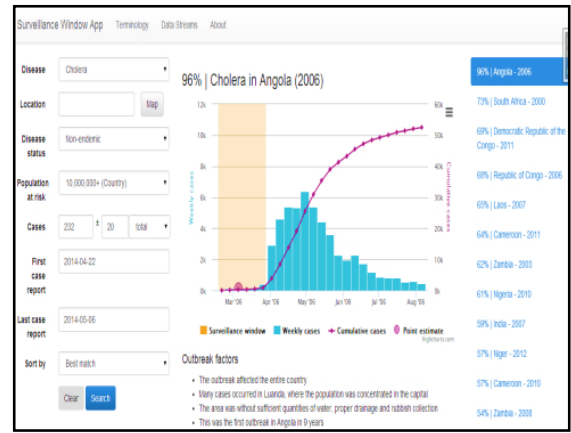

